\title{
Articulation Performance of Patients Wearing Obturators with Different Buccal Extension Designs
}

\author{
Suha Turkaslan ${ }^{a}$ \\ Timucin Baykul \\ M. Asim Aydinc \\ M. Mustafa Ozarslana
}

\section{ABSTRACT}

Objectives: The primary goal of prosthetic obturation is closure of the maxillectomy defect and separation of the oral cavity from the sino-nasal cavities by use of different bulb designs. The aim of this study was to evaluate the articulation performance of obturator patients with three different buccal extension designs.

Methods: Five patients with palatal defects of comparable sizes at ages ranging from 42 to 74 were evaluated. Starting at postoperative 4 months, speech intelligibility (SI) was assessed without a prosthetic obturator and with an obturator of buccal extensions $15 \mathrm{~mm}$ (high), $10 \mathrm{~mm}$ (medium) and $5 \mathrm{~mm}$ (low), respectively. Assessments were performed at four week intervals for adaptation. The articulation performance of patients with different buccal extension designs were evaluated on speech intelligibility. The data tested using Friedman test.

Results: The mean SI score without an obturator was $45.04 \% \pm 5.86 \%$. SI was found to be significantly increased with obturators of any buccal extensions with the mean values $90.50 \%, \% 94.24 \%$ and $91.20 \%$ for high, medium, and low buccal extensions respectively. When the SI score was compared between three buccal extension types medium was found to be significantly higher compared to others $(P<.05)$.

Conclusions: Obturators improve speech intelligibility irrespective of their buccal extension levels. Nevertheless, medium size buccal extension enables the optimum sealing for better articulation. (Eur J Dent 2009;3:185-190)

Key words: Obturator; Bulb height; Buccal extension; Speech intelligibility.

a Department of Prosthodontics, Faculty of Dentistry, Süleyman Demirel University, Isparta, Turkey.

b Department of Oral \& Maxillofacial Surgery, Faculty of Dentistry, Süleyman Demirel University, Isparta, Turkey.

Department of Plastic \& Reconstructive Surgery, Faculty of Medicine, Süleyman Demirel University, Isparta, Turkey.
Corresponding author: Assist. Prof. Dr. Suha Turkaslan Suleyman Demirel University Faculty of Dentistry, Department of Prosthodontics Isparta, TURKEY

Phone: +902462113263

Fax : +902462370607

E-mail : suhaturkaslandyahoo.com 


\section{INTRODUCTION}

Prosthetic rehabilitation of patients with acquired maxillary defects has played an important role in improving their quality of life. ${ }^{1,2}$ The effect of prosthetic rehabilitation in oral cancer patients should be evaluated from different aspects. One of them is speech which is usually interrupted after maxillary resection. Speech is a function carried through the combination of respiratory, laryngeal, velopharyngeal and articulatory systems. A breakdown in one of these systems may result in malfunction. ${ }^{3}$ Maxillary extension of cancers can leave the patient with large communications between the oral and nasal cavities that drastically impair speech intelligibility (SI). ${ }^{4}$

There are different claims concerning the bulb height of the obturators. Some advocate a bulb should be as high as possible for a better peripheral seal whereas some advise to keep it at a minimum with the same concern. ${ }^{5-8}$ Although a high bulb design could be thought to perform better regarding sealing, increased weight may inevitably lead to an impaired retention and stability. 9,10 On the other hand, as the bulb size diminishes capability of sealing becomes a problem adversely affecting the speech performance. ${ }^{11-20}$

To date, the relationship between the height of buccal extension and word processing was not investigated. The purpose of this study was to compare obturator prostheses with low, medium or high extensions with respect to their effect on speech intelligibility.

\section{MATERIALS AND METHOD}

Inclusion criteria of this study were defined as the maxillary resections involving one side of the hard palate keeping the soft palate and the other side of hard palate intact, and no known articulation problems prior to operation. Five patients were admitted to the study with ages 4274.

\section{Obturator construction process}

After removal of the tumor, pre-surgically constructed immediate obturator applied right after surgery. The immediate (surgical) obturator was used to close the resection, to hold surgical dressings, and to provide limited physiologic assistance for speech and deglutition. Ten days after surgery an interim obturator that is to be used for 3 months was built. The interim obturators served for three purposes: to give patients practice in retaining the prosthesis in the mouth, to provide a period of observation for evaluating potential neoplastic recurrence, and to allow time for healing and tissue shrinkage. For the construction of definitive obturator irreversible hydrocolloid (Cavex Impressional; Cavex Holland BV) impressions were made with stock impression trays (Osung Industrial, Kimpo, Korea) to fabricate individual impression tray. A metal framework was fabricated of Chrome- Cobalt alloy (Biosil-l) by use of cast model which obtained utilizing light polymerized acrylic impression tray and irreversible hydrocolloid impression material. The buccal extension type of obturator, which had a wall thickness of approximately $2 \mathrm{~mm}$, was processed in the standard manner, using heatpolymerizing acrylic resin (Meliodent, Heraeus Kulzer, Germanyl. The buccal extension of the obturator was about $15 \mathrm{~mm}$ above the lateral scar band and referred as high (H) (Figure 1). Four weeks later, the extension of the obturator was reduced to $10 \mathrm{~mm}$ to produce medium (M) (Figure 2) obturator type. Final reduction of the obturator was carried out after another four week interval to have a prosthesis with a $5 \mathrm{~mm}$ buccal extension referred as low (L) (Figure 3).

During the follow up special efforts were made to attain a close fit between the prosthesis and surrounding tissue to preclude leakage of air into the nasal cavity during speech. The permanent obturator was designed to achieve the best possible result for each patient in terms of oralfacial cosmetics and function.

\section{Articulation test}

Just prior to the application of $\mathrm{H}$ permanent obturator the articulation was evaluated without prosthesis by using a speech intelligibility test. The test was repeated at four week intervals and then the buccal extension was reduced. The SI tests of obturator $\mathrm{H}, \mathrm{M}$ were applied just prior to the wearing of obturators $M$ and $L$, respectively. The SI test of obturator $L$ was applied following a four week interval of obturator $L$ wearing. So four SI tests (no obturation, $H, M, L$ ) were obtained for each patient. By using a standard tool in Turkish that was demonstrated to be valid for measuring $\mathrm{SI}$ was utilized. ${ }^{21,22}$ The test tool was comprised of ten 
groups of words. Each group contained 17 words that came one after the other without any relations in meaning. The performance of the patients were recorded in a quiet room where the patients were seated comfortably facing a microphone placed $15 \mathrm{~cm}$ from the mouth. The assessments of the recordings were done by two investigators (S.T, M.M.O). The speech samples from each patient with varying buccal extensions were presented in random order so that the listener was unaware of the patients' obturator design. Intelligibility of each word was evaluated separately and was assessed as negative or positive with the consensus of both

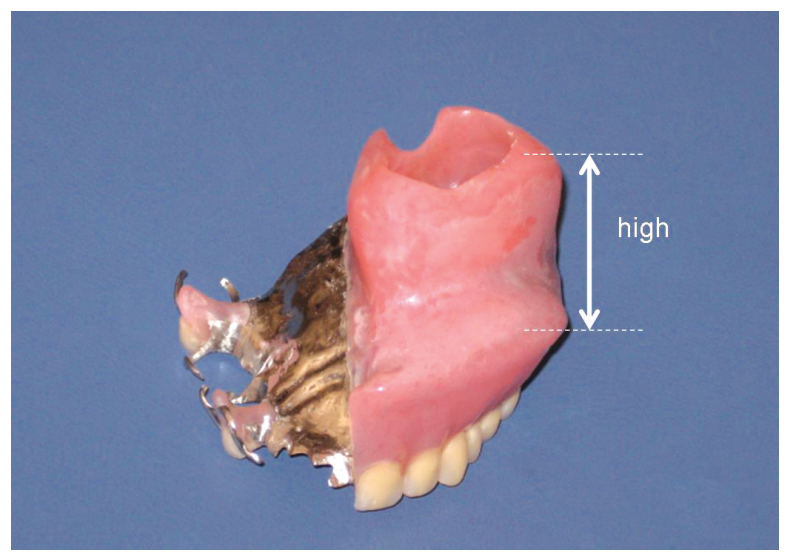

Figure 1. Obturator with high buccal extension design.

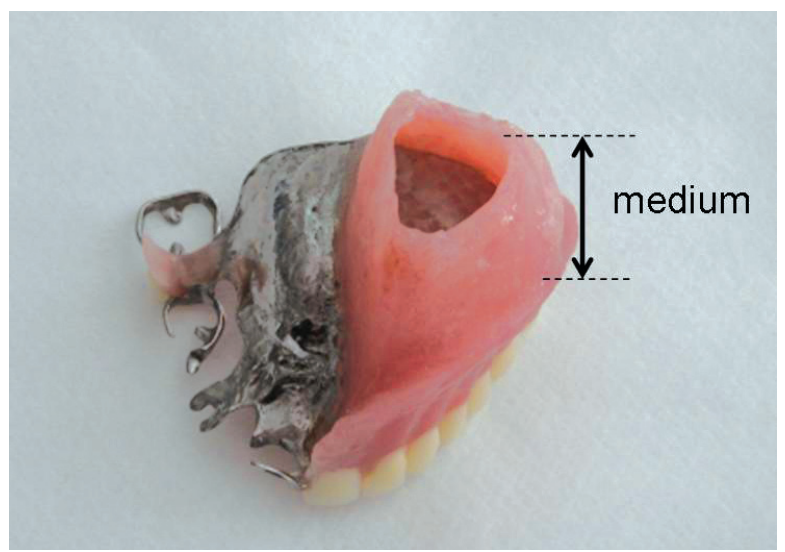

Figure 2. Obturator with middle buccal extension design. investigators. The percentage of words assessed as positive for intelligibility was calculated to give SI score.

Data analyses

The SI scores with three different types of obturators were compared by using Friedman test which is the non parametric analogue of repeated measures by using SPSS (SPSS Inc., Chicago, Illinois, USA) statistical package.

\section{RESULTS}

The SI scores without an obturator and with three types of obturators are displayed in Table 1. The obturators increased speech intelligibility prominently irrespective of their buccal extensions (Table 2). Therefore the comparison was made among the three types of obturators. The obturator with medium type of buccal extension was found to be superior to the other two types with respect to $\mathrm{SI}(\mathrm{P}<.05)$.

\section{DISCUSSION}

We found that maxillary prostheses of any buccal extension drastically improve the speech intelligibility of maxillary resection patients.

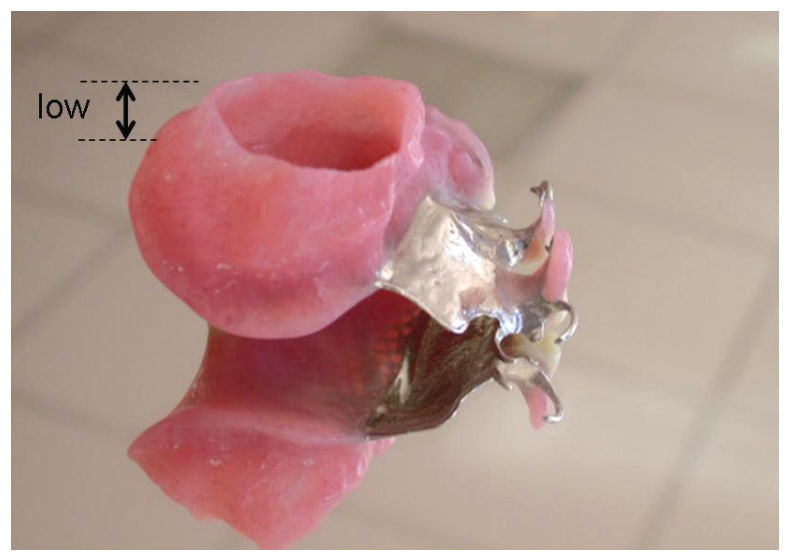

Figure 3. Obturator with low buccal extension design.

Table 1. The scores recorded from five patients with three different buccal extension designs.

\begin{tabular}{|c|c|c|c|c|}
\hline Subjects & $\begin{array}{c}\text { Without Obturation } \\
\% \text { Score }\end{array}$ & $\begin{array}{c}\text { High Obturator } \\
\% \text { Score }\end{array}$ & $\begin{array}{c}\text { Medium Obturator } \\
\% \text { Score }\end{array}$ & $\begin{array}{c}\text { Low Obturator } \\
\% \text { Score }\end{array}$ \\
\hline 1 & 37.80 & 90.50 & 92.40 & 88.00 \\
\hline 2 & 43.40 & 93.20 & 93.40 & 92.30 \\
\hline 3 & 44.00 & 91.00 & 96.00 & 92.00 \\
\hline 4 & 54.00 & 88.40 & 94.00 & 89.40 \\
\hline 5 & 46.00 & 89.40 & 95.40 & 94.30 \\
\hline$\%$ Mean Score & 45.04 & 90.50 & 94.24 & 91.20 \\
\hline
\end{tabular}


Though, a moderate size buccal extension performs better than high or low. Restoring the patient to a normal function and maintaining satisfactory facial appearance is the basic aim of prosthetic rehabilitation. Intelligibility of articulation with an oronasal surgical defect may probably be the first problem to be encountered by patients following maxillectomy since speech is a social instrument. ${ }^{12}$ The standard measurement of communicative function is speech intelligibility. ${ }^{13}$

Aramany and Oral suggested that the size and bulb type (the buccal flange type or the hollow type), affect voice quality. Although bulb size has been speculated related to articulation it has not been systematically investigated concerning speech intelligibility. Designs of maxillary obturator bulb are affected by the size and location of the defect and availability of tissue undercuts around the defect size. ${ }^{14}$ The most frequent maxillary defect is the case classified as Aramany's Class I which is the classical hemimaxilectomy defect. ${ }^{15,16} \mathrm{We}$ investigated the relation between buccal extension and speech intelligibility with a constant variable of maxillary defect type of Aramany Class I. In previous studies on Aramany Class I defects, the lowest mean SI scores without obturation were found to be $35.7-61 \% .{ }^{17.18}$ It was $45.04 \%$ in our study.

Concerning the nasal extension, Brown ${ }^{19}$ and Desjardins ${ }^{6}$ have suggested that the lateral wall of the bulb should be extended higher geometrically. Bummer et $\mathrm{al}^{1}$ reported that the superior height of medial palatal extension should terminate at the junction of the oral and respiratory mucosa, or at the level of the nasal floor, as further extension medially would only serve to impede nasal airflow. The medial and lateral heights were kept equal in our prostheses with three different buccal extensions. Buccal extension occasionally has to

Table 2. The SI scores recorded with or without obturation.

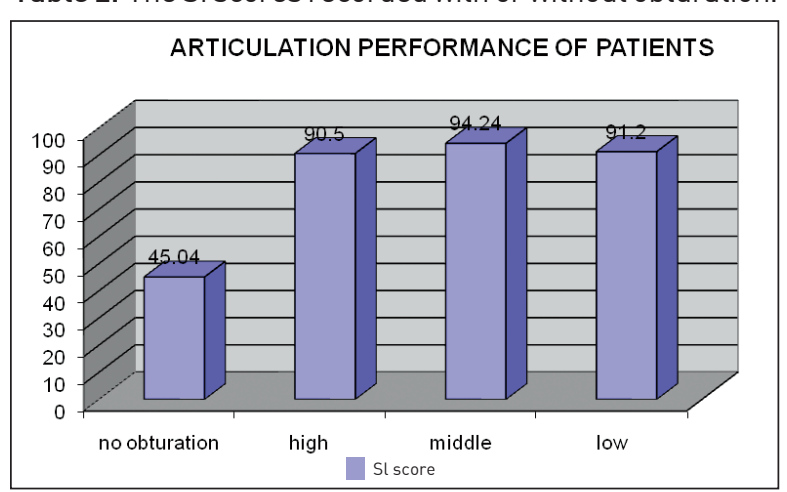

be limited, in cases with limited mouth opening. On the other hand it is not necessary to fill the entire defect since filling the cavity with a mass of acrylic not only adds unwanted weight to the prosthesis, but also impairs speech quality. ${ }^{7}$

Adisman $^{8}$ stated that if the defect is limited to the hard palate area, it is sufficient to cover the defect and create a seal by engaging a minimal amount of undercuts. Aramany and Drane ${ }^{15}$ indicated that the use of small nasal extension sections in hollow obturators in patients with large palatal defects tends to improve voice quality, but with smaller defects, the size of the nasal extension section has little effect on voice quality. Buccal flange obturators showed statistically significant superiority to hollow obturators with live and tape-recorded speech evaluations. ${ }^{16}$

The degree of extension into the defect varies depending upon the configuration of the defect, character of its lining tissue, and functional requirements for retention, support, and stabilization of the prosthesis. ${ }^{5}$ In large defects lacking palatal support, the obturator is aggressively extended vertically to engage the surgical defect and horizontally to the lateral aspect of the orbital floor, at the expense of its size and weight. Remaining structures are subjected to continuous stresses from such large, heavy obturators, jeopardizing the health of the tissues, and compromising patient function and comfort. To reduce the weight of the prosthesis, the bulb portion of the obturator is generally hollowed after it has been processed into acrylic resin. Weight reduction is especially important when the obturator prosthesis is suspended without bony or posterior tooth support on the defect side, as is the case with most maxillary resection prostheses. $9,10,19$

To prevent liquid and food leakage into the nasal cavity, the bulb of the obturator is placed tightly into the defect area; however, the surrounding soft tissue changes its shape during the very common activities of mastication, swallowing, and speech. $9,10,18-20$

High construction is preferred for better soft tissue support, retention and stabilization. On the other hand it is compromised in patients with limited mouth opening. Low compliance of patients and weight are the other disadvantages of higher design. High and heavy obturators may 
lead to excessive stresses and compromise the health of the supporting tissues and also comfort of the patient. In the present study high buccal extension design may result in a heavy obturator dislodging from the supporting tissues and low design may fail to seal the defect area resulting in lower SI scores.

Speech intelligibility in maxillary resection patients depends on many variables other than the buccal extension of the obturator. Among them the defect size and location, status of the abutment teeth with respect to the stability, number and localization, the status of the soft tissue with respect to undercuts and resilience, patient factors which are mostly related to motivation are the principal ones. Therefore the buccal extension should be determined by adjusting the other variables. Starting with a high design and gradually decreasing the buccal extension during periodical rebasings which are usually required to adapt the soft tissue changes until the optimum comfort and speech intelligibility is reached can be the best way of management to obtain the ideal prosthesis.

Limitations of this study include the relatively small sample size, which might prevent the authors to make conclusions regarding some factors such as patient preference among obturator height because of respective lack of enough data for more detailed statistical evaluation. Further investigations with a large sample size that also evaluate other variables more than solely bulb height may permit a multivariate analysis.

\section{CONCLUSIONS}

A moderate buccal extension should be selected after gradually decreasing the bulb height for improved speech intelligibility in the most common type of surgical defects.

\section{REFERENCES}

1. Bummer J III, Curtis TA, Marunick MT. Maxillofacial Rehabilitation. St. Louis, Ishiyaku Euro America, Inc; 1996:225-284

2. Patton DW, Ali A, Davies R, Fardy MJ. Oral rehabilitation and quality of life following the treatment of oral cancer. Dental Update 1994;21:231-234.

3. Mahanna GK, Beukelman DR, Marshal JA, Gaebler CA, Sullivan M. Obturator prostheses after cancer surgery: An approach to speech outcome assessment. J Prosthet Dent 1998;79:310-316.
4. Emily AT, Jack L. Acoustic analyses of speech changes after maxillectomy and prosthodontic management. $J$ Prosthet Dent 1989;62:449-455.

5. Brown KE. Peripheral consideration in improving obturator retention. J Prosthet Dent 1968;20:176-181.

6. Desjardins RP. Obturator prosthesis design for maxillary defects. J Prosthet Dent 1978;39:424-435.

7. Sharry JJ. The meatus obturator in cleft palate prosthesis. Oral Surg Oral Med Oral Pathol 1954;7:852-855.

8. Adisman IK. Prosthesis serviceability for acquired jaw defects. Dent Clin North Am 1990;34:265-284.

9. Schwartzman B, Caputo A, Beumer J. Occlusal force transfer by removable partial denture designs for a radical maxillectomy. J Prosthet Dent 1985;54:397-403.

10. Oh WS, Roumanas ED. Optimization of maxillary obturator thickness using a double-processing technique. $J$ Prosthodont 2008;17:60-63.

11. Itsuki Murase. In-Vivo modal analysis of maxillary dentition in a maxillectomy patient wearing buccal flange obturator prostheses with different bulb height designs. J Jpn Prosthodont Soc 2008;52:150-159.

12. Arigbede AO, Dosumu 00, Shaba OP, Esan TA. Evaluation of speech in patients with partial surgically acquired defects: pre and post prosthetic obturation. J Contemp Dent Pract 2006;15;89-96.

13. de Carvalho-Teles V, Pegoraro-Krook MI, Lauris JRP. Speech evaluation with and without palatal obturator in patients submitted to maxillectomy. J Appl Oral Sci 2006;14:421-426.

14. Oki M, lida T, Mukohyama H, Tomizuka K, Takato T, Taniguchi $\mathrm{H}$. The vibratory characteristics of obturators with different bulb height and form designs. J Oral Rehabil 2006;33:43-51.

15. Aramany MA, Drane JB. Effect of nasal extension sections on the voice quality of acquired cleft palate patients. $J$ Prosthet Dent 1972;27:194-202.

16. Oral K, Aramany MA, McWilliams BJ. Speech intelligibility with the buccal flange obturator. $J$ Prosthet Dent 1979;41:323-328.

17. Umino S, Masuda G, Ono S, Fujita K. Speech intelligibility following maxillectomy with and without a prosthesis: an analysis of 54 cases. J Oral Rehabil 1998;25:153-158.

18. Sullivan M, Gaebler C, Beukelman D, Mahanna G, Marshall J, Lydiatt D, Lydiatt WM. Impact of palatal prosthodontic intervention on communication performance of patients' maxillectomy defects: a multilevel outcome study. Head Neck 2002;24:530-538.

19. Brown KE. Clinical considerations improving obturator treatment. J Prosthet Dent 1970;24:461-466. 
20. Kobayashi M, Oki M, Ozawa S, Inoue T, Mukohyama $H$, Takato T, Ohyama T, Taniguchi $H$. Vibration analysis of obturator prostheses with different bulb height designs. $J$ Med Dent Sci 2002;49:121-128.

21. Hasanreisoḡlu U, Gürbüz A, Belgin E. Speech intelligibility in various types of obturators constructed after maxillary resections. Ankara Univ Dis Hekim Fak Derg 1989;16:77-86.

22. Özbek M, Tulunoḡlu I, Özkan S, Öktemer M. Evaluation of articulation of Turkish phonemes after removable partial denture application. Braz Dent J 2003;14:125-131. 